\title{
Endosphere microbiome assemblage in scented black rice is affected by plant development, with possible functional roles
}

K. Malabika Singha

Assam University

Brahmanand Singh

National Botanical Research Institute Lucknow

Dinesh Kumar Maheswari

Gurukula Kangri vishwavidyalaya

Piyush Pandey ( $\Delta$ ppmicroaus@gmail.com )

Assam University https://orcid.org/0000-0002-0300-2349

Research

Keywords:

Posted Date: January 10th, 2020

DOI: https://doi.org/10.21203/rs.2.19892/v2

License: (c) (i) This work is licensed under a Creative Commons Attribution 4.0 International License.

Read Full License 
The authors have withdrawn this preprint from Research Square 